\title{
CORRECTION
}

View Article Online

View Journal I View Issue

D) Check for updates

Cite this: RSC Adv., 2021, 11, 23418

DOI: $10.1039 / d 1$ ra90128a

rsc.li/rsc-advances

\section{Correction: A simple and straightforward synthesis of phenyl isothiocyanates, symmetrical and unsymmetrical thioureas under ball milling}

\author{
Ze Zhang, ${ }^{*}$ Hao-Hao Wu and Ya-Jun Tan \\ Correction for 'A simple and straightforward synthesis of phenyl isothiocyanates, symmetrical and \\ unsymmetrical thioureas under ball milling' by Ze Zhang et al., RSC Adv., 2013, 3, 16940-16944, DOI: \\ 10.1039/C3RA43252A.
}

The authors regret that it was not clear in the original article that part of the graphical abstract image had been reproduced from the graphical abstract of an earlier ChemComm paper. ${ }^{1}$ Although the ChemComm article was cited as ref. $15 b$, and here as ref. 1 , it was not made clear that some of the image was reproduced from this article.

The Royal Society of Chemistry apologises for these errors and any consequent inconvenience to authors and readers.

\section{References}

1 V. Štrukil, D. Margetić, M. D. Igrc, M. Eckert-Maksić and T. Friščić, Chem. Commun., 2012, 48, 9705-9707, DOI: 10.1039/C2CC34013E. 